\title{
Strategies for Environmental Monitoring
}

\author{
from “Emerging Environmental Issues" by Ted Munn, Peter Timmerman, and Anne Whyte, in BAMS, July 2000, \\ based on the Walter Orr Roberts Lecture at the 2000 AMS Annual Meeting
}

A major component to be included in a strategy for "managing" emerging environmental issues is the creation of early warning monitoring systems. One of the main difficulties in achieving this goal is the large amount of noise surrounding environmental signals...With this in mind, the best early warning indicators may often be obtained from measurements of the socioeconomic drivers of environmental change. As a simple example, a search for upward trends in the frequency and intensity of surface ozone episodes is more likely to be successful if based on trends in regional emissions of oxides of nitrogen from automobiles, power stations, and air conditioning equipment than from time series of ozone concentrations. In many such cases, of course, there will be need for well-formulated models of the system as a whole. Historical experience with the issues of stratospheric ozone depletion, acidic deposition, and climate warming shows that only when the fundamental processes involved are reasonably well understood can future trends be estimated with sufficient confidence to be used in policy applications...

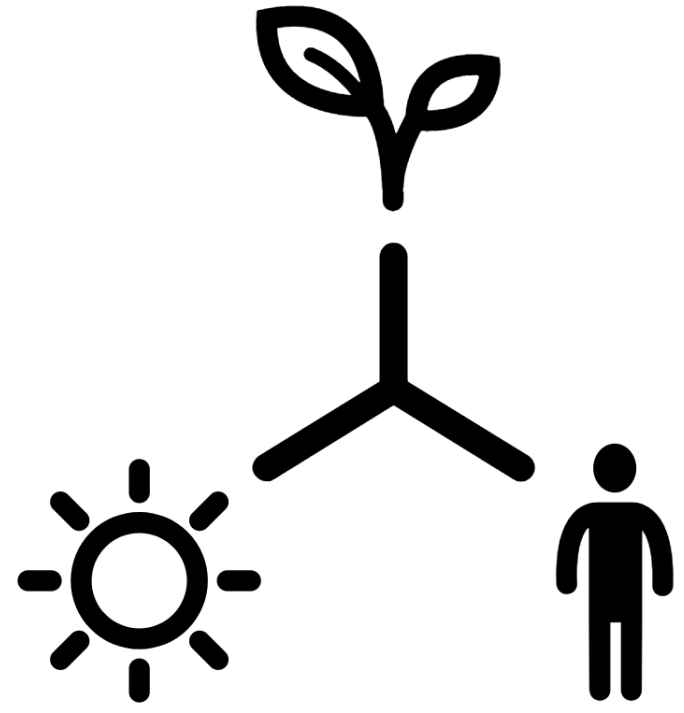

[F]ive general criteria can be listed for use in the development of early warning monitoring systems.

I) Always use the ecosystem approach. For example, choose a watershed or other holistic

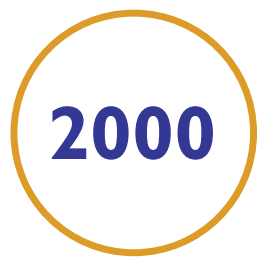
scale, and include interactions and feedbacks among the system components.

2) Try to visualize surprises. Factor in a few not impossible scenarios: if one of them were to happen, what kinds of data would provide the earliest possible warning?

3) Use simulation models when appropriate.

4) Use existing monitoring systems wherever possible but only after critical assessment of their relevance. (Considerable resources are required to create and operate monitoring systems so as much use as is feasible should be made of available data.)

5) Always use the adaptive approach. Particularly in the case of emerging issues, the design of an early warning monitoring system ought to be reviewed periodically (at least once every two years) by a group of environmental scientists and stakeholders...

[E]merging environmental issues in the twentyfirst century....are largely transformations of old issues, continually evolving and broadening. Several decades ago, climate change was a subject to be studied by climatologists. Later, oceanographers were added to the team, then glaciologists, and finally ecologists. Now the door is opening for engineers, health scientists, and social scientists....

As pointed out by Jasanoff et al. (1997), The physical sustainability of the biosphere is now seen to be inseparably bound up with issues of economic development, social equity, and international peace and security.

To read this article in the BAMS archives, see

https://journals.ametsoc.org/doi/pdf// 0.I I 75//520-0477\%282000\%2908I\%3C I603\%3AEEI\%3E2.3.CO\%3B2 


\section{AMS Publications introduces}

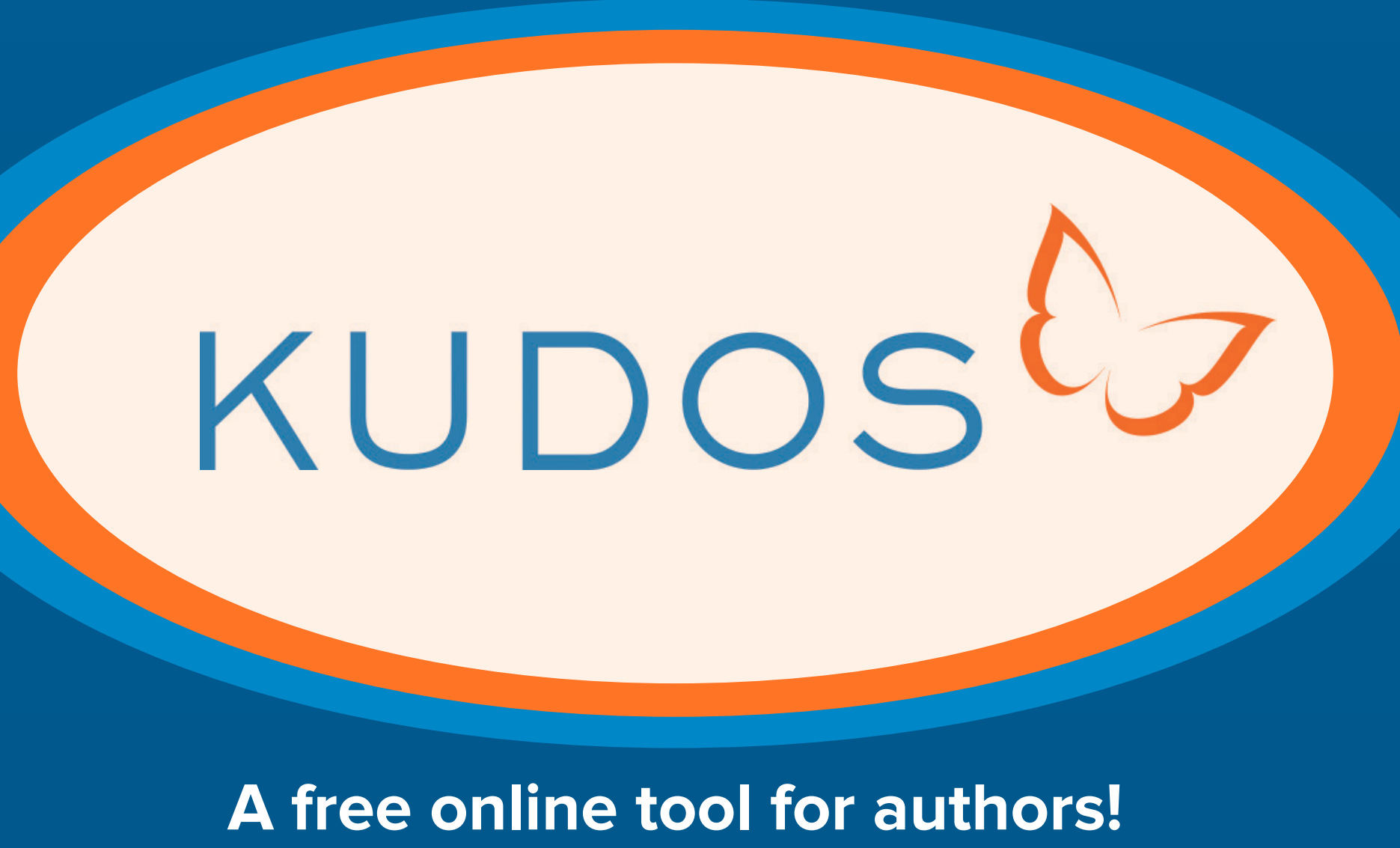

\section{Communicate Your Research More Effectively}

\section{Increase Your Work's Impact}

- Maximize citations and downloads of your article

- Open up your research to new audiences

- Explain and share your work in only 10 minutes

- Increase full-text article downloads by $23 \%$

- Access publication metrics via the author dashboard

Learn more about using Kudos with AMS

https://www.ametsoc.org/kudos/ 